\title{
Promyelocyte to Lymphocyte Ratio Measurement
}

National Cancer Institute

\section{Source}

National Cancer Institute. Promyelocyte to Lymphocyte Ratio Measurement. NCI

Thesaurus. Code C74653.

The determination of the ratio of promyelocytes compared to all lymphocytes present in a sample. The measurement may be expressed as a ratio or percentage. 